\title{
El funk de Río de Janeiro y las comunidades: \\ entre la prohibición por ley y la pacificación por la guerra
}

\author{
The funk of Rio de Janeiro and communities: between the prohibition \\ by law and peace by war
}

\author{
Ary Pimentel
}

Recibido: 1 de Marzo 2012. Aprobado: 10 de Abril de 2012

\begin{abstract}
Resumen
En un momento en que continúan los operativos contra favelas y se realizan múltiples intervenciones urbanas en la ciudad de Río de Janeiro para albergar los Juegos Olímpicos y parte del Campeonato Mundial de Fútbol de 2014, destacándose la puesta en escena de una narrativa propia de un estado de guerra con unidades de élite de la Policía Militar, Policía Civil y efectivos del Ejército penetrando en comunidades apoyados por tanques y helicópteros de combate, parece importante intentar fugarse al encanto mediático y desplazar la mirada de la crítica a los discursos que representan la realidad desde el otro lado de la trinchera donde la ausencia del Estado y el domino del narco está generando otra forma de vida. Con una historia del proceso de formación y los cambios recientes de una de las más potentes manifestaciones culturales de las periferias latinoamericanas (el Funk Carioca) y el análisis de algunos aspectos destacados de un corpus formado por letras que incluyen los datos duros y sangrientos del mundo de la violencia armada, el ensayo, intenta dar cuenta de la importancia del Funk Prohibido o "Proibidão" para el estudio de la cultura popular contemporánea en Rio e intenta pensar, también, las metamorfosis por que pasa ese discurso en tiempos de "pacificación" de las barriadas populares cariocas donde las fuerzas del orden se comportan con los residentes a la manera de un ejército de ocupación. La articulación del discurso de lo "prohibido" y las crónicas de la ciudad con sus personajes criminales

Poligramas 37, primer semestre 2013, ISSN 0120-4130. 
y simples habitantes de las regiones de exclusión y segregación permite pensar una textualidad nueva como lugar de escenificación de una ficción narrativa con poderoso papel para la sociabilidad de estos territorios. Leer estas músicas que cuentan las vivencias del mundo narco en la ciudad de Río de Janeiro (Brasil) aparece, así, como un intento de comprender el fenómeno no como un asunto policíaco, sino como elemento revelador de los procesos de representación desde abajo, desde los de abajo y sus propios balbuceos.

Palabras clave: favela; funk carioca; narco ritmos; música de la periferia; nación.

\begin{abstract}
At one point in continuing operations against urban slums and multiple procedures are performed in the city of Rio de Janeiro to host the Olympic Games and the World Cup 2014, highlighting the staging of a narrative of a state own war in elite units of the Military Police, Civil Police and army troops backed by tanks penetrating and helicopter gunships communities, it seems important to try to escape media charm and move the gaze critique discourses that represent reality from the other side of the trench where the absence of the state and the dominance of the drug is generating another way of life. With a history of the formation and the recent changes in one of the most powerful manifestations of Latin American cultural peripheries ( the Funk Carioca) and analysis of some highlights of a corpus of letters that include hard and bloody world data armed violence, the essay attempts to explain the importance of Funk spaces or "Proibidão" for the study of contemporary popular culture in Rio and tries to think, also, the metamorphosis that speech happens in times of "peace" of Rio's shantytowns where the police behave with residents in the manner of an occupying army. The articulation of the discourse of the "forbidden" and chronicles of the town with their criminal and simple inhabitants of the regions of exclusion and segregation characters suggests a new textuality as a place of staging a narrative fiction with powerful role for the sociability of these territories. Read this music which feature the experiences of narco world in the city of Rio de Janeiro (Brazil) appears thus as an attempt to understand the phenomenon not as a police matter, but as revealing element of the processes of representation from below, from those below and your own babbling.
\end{abstract}

Keywords: Favela; funk carioca; narco rhythms; music from the periphery; nation. 
La barbarie no sólo dramatiza el enfrentamiento

con la civilización, sino también un segundo

enfrentamiento, consigo misma.

Josefina Ludmer

\section{ESCENA 1}

Fuerzas policiales movilizan 510 hombres entre militares y civiles para ocupar Vila Cruzeiro, en el barrio de Penha el 25 de noviembre de 2010, por la mañana. El Batallón de Operaciones Especiales de la Policía invade la "favela" (villa miseria o chabola), considerada el Cuartel General del Comando Vermelho (Comando Rojo), en coches blindados de la policía y tanques de la Marina brasileña. Los traficantes huyen a la favela vecina. Setenta marineros ayudan a manejar los carros de combate blindados de la Marina, guarnecidos con ametralladoras .50. Son estas patrullas que permiten a la policía de Rio entrar en la comunidad y trasponer las barricadas improvisadas por los traficantes. Las imágenes de un helicóptero de la TV Globo muestran en vivo la huída en masa de los narcos de Vila Cruzeiro hasta el Complexo do Alemão por Serra da Misericórdia. La repercusión de las imágenes fue inmediata. Era posible constatar sonido de explosiones y humo en distintos puntos de la favela. "Se convirtió en una guerra civil", sintetizó una residente. Marina, Ejército y Aeronáutica entran en la guerra de Rio. (Periódico $O$ Estado de São Paulo, 25 de noviembre de 2010.)

\section{ESCENA 2}

Un grupo de jóvenes oye música funk a alto volumen en una calle de Cidade de Deus, en la Zona Oeste de Rio de Janeiro. Policiales de la Unidad de Policía Pacificadora (UPP), instalada en esta "favela" en febrero de 2009, abordan al grupo con el argumento de que la música hace apología al crimen. Un residente se presenta como dueño del aparato, pero se niega a apagarlo. Tampoco concuerda en entregarles el CD que tocaba y es detenido por los policías. Los demás residentes lo defienden y los policías disparan para contenerlos, resultando herido uno de los jóvenes, que es llevado al hospital. (Periódico O Dia, 8 de septiembre de 2011.)

Estas escenas sintetizan los elementos que constituyen los dos marcos-límite del período en que se estructuró la manifestación cultural objeto de este estudio: el Funk Prohibido carioca, es decir, la música electrónica producida en las orillas populares de la ciudad de Rio de Janeiro, Brasil. Podemos considerar como factor de origen de este subgénero del funk carioca la propia ley que impuso la clandestinidad de los espectáculos musicales relacionados al mundo funk y, de modo 
particular, de las vertientes de funk que exploran más explícitamente los temas de la sexualidad o de la violencia asociada a las facciones del tráfico de drogas al menudeo, producción también conocida por el nombre de "proibidão" 2008, con la implantación de las Unidades de Policía Pacificadora (UPPs), llevando a la retomada por el Estado de territorios hasta entonces controlados por las redes del narcotráfico, pero que tiene su momento clave en la ocupación de la Vila Cruzeiro, en 25 de noviembre de 2010, fue el segundo corte temporal que nos permitió ubicar la producción del Funk Prohibido en un período determinado. Con una resonancia que se pudo sentir ya en los días siguientes, la ocupación de Vila Cruzeiro y, tres días después, la ocupación del conjunto de "favelas" del Morro do Alemão, pareció señalar el comienzo de un nuevo período en las representaciones de las periferias cariocas y en el discurso del funk prohibido, que había ganado sus contornos definitivos en el último año del siglo XX como un tipo de "paisaje sonoro" directamente vinculado a las "facciones" o "comandos" antagónicos que compiten de manera violenta por el territorio o el control del negocio de la droga.

He aquí, en los arrabales de la ciudad de Rio de Janeiro, Brasil, la posibilidad de interpretar algunos de los procesos sociales y culturales involucrados en la realidad de la periferia de una metrópolis a través de los discursos compuestos y cantados por los propios sujetos subalternos residentes de una región marcada por el estigma de la pobreza y la violencia, los cuales pudieron a través de un ritmo electrónico profundamente híbrido sintetizar una riquísima "micro-cultura" urbana. La década de 2001 a 2010 asiste a la etapa de resignificación del rol mismo de las formas musicales del funk como elemento cultural creado por un orden distinto y a la vez como espacio de estructuración de este orden.

Considerando la necesidad histórica de reconocimiento de estas representaciones que constituyen un discurso singular marcado por el lugar de habla de estos sujetos subalternos, buscamos leer la realidad cultural de los espacios segregados de la ciudad de Rio de Janeiro a través de fragmentos dispersos de la trayectoria de esa dicción particular del funk, siguiendo la orientación de Roberto

\footnotetext{
${ }^{4}$ En sus dos vertientes principales, el "proibidão" recibió diversas denominaciones. Sigue una lista de las más frecuentes, segundo el propio lenguaje de los vendedores de CDs de música prohibida con los que nos relacionamos a lo largo de la investigación: "rap prohibido", "funk del contexto", "funk de facción", "música de bandido", "chisme del crimen", "música de traficante" o, en una segunda vertiente, "funk putería", "puro sexo", "pornofunk", "música con palabrotas"...

Poligramas 37, primer semestre 2013, ISSN 0120-4130. 
Damatta que, en Conta de mentiroso: sete ensaios de antropologia brasileira, reconoce y enfatiza la posibilidad de leer el mundo social a través de representaciones imaginarias masivas: "la música popular, tanto cuanto la política, la economía, la religión, la literatura erudita, las leyes y las costumbres (...) es vehículo a través del que la sociedad se revela, dejándose percibir como totalidad dinámica, viva y concreta: como universo eventualmente dotado de identidad." (DAMATTA, 1994, p. 60).

Porque consideramos, como Maingueneau (2008), la indisociabilidad de la relación que se establece entre el discurso y el cuadro social en que se da su producción y circulación, creemos que el proibidão nos ofrece innumerables pistas para rastrear la transformación de la realidad social a través de una formación discursiva particular, que asume la función de representar a los sujetos que actúan en el mundo de la margen y de la marginación urbana.

Nuestra mirada abarca desde los primeros vestigios del proibidão, cuando fue oficializada efectivamente la prohibición a comienzos de 2000, hasta los días actuales. Es justamente la producción del movimiento funk desarrollada en este intervalo de tiempo que presenta una mayor carga de violencia, motivo y consecuencia que hace que esta producción permanezca, en gran medida, silenciada a lo largo de este período en casi todos los segmentos de la ciudad formal.

Es probable que se haya empezado a utilizar el término "Funk Prohibido" o "proibidão" ya en el final de la década de $1990^{5}$, dado que desde las primeras grabaciones, como "Melô da mulher feia" o "Mulher feia cheira mal como urubu" ${ }^{6}$, encontramos la estrategia de composición de dos letras para un mismo funk: una primera para ser tocada en vivo en los "bailes" (bailantas de música funk) y otra más suave o inocente para grabación y difusión en espacios en donde la primera letra sufriera restricciones. Sin embargo, sólo después de la ley, que presentaba una clara

\footnotetext{
${ }^{5}$ En 1997, Micael Herschmann publica una colectánea de ensayos de investigadores que en aquél momento se dedicaban al tema (Abalando os anos 90: funk e hip hop: globalização, violência e estilo cultural) y no observamos el registro del término en ninguno de ellos. Hay referencias a "gangsta rap" o "rap de contexto" como versión gangsta, "pirata», producida por los funkeros y que era eventualmente cantada en los bailes de las comunidades pobres periféricas" (HERSCHMANN, 1997, p. 216). Sin embargo, el sintagma "Funk Prohibido" o el término equivalente "proibidão" todavía no había sido incorporado a la discusión.

${ }^{6}$ Se considera "Melô da mulher feia", música cantada por MC Abdulah, el primer funk carioca grabado. La música integra la colectánea Funk Brasil, de 1989, producida por el DJ Malboro. Los títulos pueden ser traducidos por: "Pegajosa de la mujer fea" y "Mujer fea huele mal como un buitre". Las "melôs" fueron músicas con melodía de estructura muy simples que proponían traducciones arbitrarias a una a letras originalmente compuesta en inglés. Pese a los absurdos de las letras, eran fáciles de cantar, puesto que la música-base ya se había difundido en las bailantas ("bailes”) de los barrios pobres de la ciudad.
}

Poligramas 37, primer semestre 2013, ISSN 0120-4130. 
intención de silenciamiento de esas dicciones periféricas, es que un cierto tipo de funk cuya difusión ya sofría restricciones bajo la alegación de un presumido "atentado violento al pudor" y de "apología del delito" empezará a llevar en su propia definición el significado de la prohibición impuesta no sólo a su difusión sino a la realización de las fiestas que se promovían como verdaderos ritos comunitarios.

Después de una fase de gran éxito en que el funk se ha "glamourizado" (HERSCHMANN, 2000), ocupando un expresivo espacio en radios y programas de televisión a mediados de los años de 1990, se desencadenó una creciente campaña de criminalización que primero tuvo como blanco a los "bailes de corredor" o "bailes de riña", como eran conocidos, para luego asociar múltiples manifestaciones de violencia registradas en la ciudad a los "bailes" funk y a los funkeros en general. Esta atmósfera fomentada por los medios de comunicación que señalan el mundo funk como causante de distintos tipos de delito llevaría a la constitución de una Comisión Parlamentar de Investigación para tratar el asunto, la CPI del Funk de la cual resultaría la ley de prohibición?

Con las restricciones legales, la responsabilidad por todo que se vinculara al baile funk recaería no sólo sobre el organizador del evento, sino especialmente sobre los presidentes, directores y gerentes de las entidades deportivas, sociales y recreativas en donde los bailes fueran realizados. Con eso, se intentaba implicar a los responsables por los espacios cedidos para la realización de los bailes, volviendo a éstos inviables en la práctica. Se buscaba así eliminar uno de los pocos canales de expresión con que contaba un número significativo de jóvenes que tenían en el funk el componente básico de su cultura. El creciente fardo de negatividad trae consecuencias inmediatas y el funk, en particular la vertiente que se vincula a lo prohibido, que ya había tenido su difusión vedada en la radio y en la televisión, a causa de la evaluación de sus contenidos, queda sin acceso a los espacios de promoción de los bailes e irá limitarse cada vez más a los espacios de las favelas.

\footnotetext{
${ }^{7}$ Curiosamente, la ley, de autoría de una Comisión Parlamentar de Investigación (CPI del Funk, instalada en Asamblea Legislativa del Estado de Rio de Janeiro en 1999 para investigar denuncias de violencia, pornografía y apología a las drogas en el interior de los bailes), fue promulgada por el presidente de la ALERJ, diputado Sérgio Cabral, que, nueve años después, se asociaría al movimiento de reconocimiento del Funk como cultura, mantenidas las restricciones a la vertiente prohibida.
}

Poligramas 37, primer semestre 2013, ISSN 0120-4130. 
La Ley no 3410, de 29 de mayo de 2000, que, según el caput, "Dispone sobre la realización de bailes tipo funk en el territorio del estado de Rio de Janeiro y da otras providencias", tenía como objetivo explícito acabar con los "bailes de corredor" , pero vuelve imposible la realización de cualquier baile funk en los espacios cerrados de la ciudad formal.

La ley con la que, según sus autores, se pretendía simplemente la reglamentación de los bailes funk era claramente discriminatoria con un género musical específico y con los jóvenes residentes de los barrios desheredados y segregados que lo apreciaban. Exigía previa autorización de la Policía Militar para la realización de los bailes ${ }^{10}$ y obligaba al organizador del evento a garantizar la presencia de policías a lo largo del evento, desde su inicio hasta su cierre, y a proveer instalación de detectores de metales en la entrada de los clubes o entidades en donde fueran realizados los bailes.

Sin embargo, aunque estas normas prácticas trajeran dificultades para la realización de los bailes, las mismas podrían ser sorteadas, sin caracterizarse de modo explícito una intención prohibitiva. Pero es precisamente en un artículo que no trata de ningún aspecto práctico vinculado a la realización de los bailes funk que podemos identificar la esencia prohibitiva y no normativa de la ley. El artículo $6^{\circ}$ dice textualmente: "Está prohibida la reproducción de músicas y procedimientos de apología del delito en los locales en que se realizan eventos sociales y deportivos de cualquier naturaleza." (Destacado nuestro.) Con eso, la ley se convierte en el instrumento que da el verdadero sentido a la expresión "Funk Prohibido" o "proibidão".

Desde este momento, sin espacio en los clubes $u$ organizaciones deportivas y con los impedimentos prácticos impuestos por la legislación en vigor, el único espacio que hay para la realización de los bailes es justo el interior de las comunidades dominadas por facciones criminales del tráfico de drogas. Ahí, en donde el Estado estaba ausente y, por lo tanto, en donde la ley no

\footnotetext{
${ }^{8}$ Legislación citada disponible en: <http://alerjln1.alerj.rj.gov.br/contlei.nsf/69d90307244602bb032567e800668618/756831a75d413aa4032568ef005562 d8?OpenDocument>. Acceso en 15 dic. 2011.

${ }^{9}$ En su artículo 5o, la Ley no 3410 determina que "La Fuerza Policial podrá cerrar el club o el local en que ocurran actos de violencia incentivada, erotismo y de pornografía, y en donde, además, se constatara el llamado corredor de la muerte." (En bastardilla en el original.)

${ }^{10}$ MATA, Fernando Luiz (DJ Malboro). In: MACEDO, Suzana. Dj Malboro. Rio de Janeiro: Dantes Editora e Livraria, Prefeitura do Rio, 2003, p. 109. (Coleção Sebastião)
}

Poligramas 37, primer semestre 2013, ISSN 0120-4130. 
tenía validez, los bailes podrían ocurrir y, a lo largo de una década, este fue un terreno fértil para la reproducción, circulación y producción de los proibidões que empezaron a transformarse en una de las vertientes más populares y polémicas del funk carioca, trascendiendo los límites de su público habitual y lanzando sus ecos hacia otros territorios de la ciudad. Fernando Luiz Mata (DJ Malboro), uno de los nombres vinculados al nacimiento del movimiento funk en Rio, define así los nuevos bailes que se proliferarían con la promulgación de la ley:

Bailanta barrial o "baile" de comunidad es la "bailanta" en el cerro, "baile" dentro de la misma favela... al aire libre, en la cuadra, en la calle... Y el "baile" de club es el "baile" del asfalto, en un club... Las personas salen de sus casas, se bañan, se visten y van al baile. En la comunidad, no, no hay eso de ir al baile, las personas ya están ahí... Uno está bañándose y ya oye al equipo de sonido tocando... Las personas del equipo empiezan ya neuróticas, empiezan ya en marcha... porque las personas ya están ahí... Entonces, en la comunidad toca menos "charme" [vertiente más bailable, romántica y consciente de la música negra carioca de los años de 80 hasta mediados de los 90$]. .$. Los "bailes" de comunidad existieron y se proliferaron a causa de la prohibición por las autoridades de los "bailes" de club. Cuando el funk fue acosado, fue recibido dentro de las comunidades, en donde él pudo sobrevivir y desarrollarse... Y las autoridades, en lugar de dejarlo dentro del club, en donde podrían mantenerlo bajo control, no... De ahí el funk empieza a asumir la cara de la realidad de las personas que viven en la favela.... ${ }^{11}$

Con la promulgación de la ley, hubo un cambio radical el en escenario funk con el gradual predominio del llamado proibidão, plasmándose a través de este funk condenado a la clandestinidad no sólo una nueva sonoridad, sino también un discurso narrativo que pondría en circulación nuevos códigos y nuevos valores, aspectos centrales de un conjunto de factores que constituyen las relaciones de sociabilidad propias de este espacio.

Por encarnar radicalmente la violencia verbal al referirse de modo directo, sin metáforas o juegos de doble sentido, a actos sexuales o a prácticas del mundo del crimen, el Funk Prohibido suscita un escándalo moral y estético. Pero el escándalo verdadero para el oyente tal vez resida primeramente en la extrañeza o en el no reconocimiento de este otro universo de valores que

\footnotetext{
${ }^{11}$ Idem, p. 42.

Poligramas 37, primer semestre 2013, ISSN 0120-4130.
} 
imperó por años o décadas en vastas áreas de la ciudad. Tal como ocurre con la lectura de los periódicos populares que visibilizan una violencia poco frecuente en las zonas urbanas que viven otro giro civilizatorio, los relatos del Funk de Facción desazonan a los que lo oyen y desazonan porque despiertan al público de su sueño con el testimonio del horror. Barren las buenas conciencias y nos acercan a lo que rechazamos porque hablan del infierno y desde el infierno. En uno de los raros textos sobre el proibidão de facción, el antropólogo Luiz Eduardo Soares, después de reconocer el fuerte impacto que las letras habían tenido sobre su sensibilidad (el de "un verdadero puñetazo en el estómago"), habla de la importancia de seguir uno de los procedimientos que la Antropología enseña: "volver de patas arriba el mensaje que los discos compactos [de Funk Prohibido] difunden, buscando, por detrás de las máscaras de odio, algún valor positivo" ${ }^{12}$. Creemos que este objetivo sólo ahora comienza a ser alcanzado por una nueva serie de trabajos de investigadores que, a ejemplo de este, empiezan a analizar con más atención la producción del funk de la última década.

\section{La pequeña nación: siguiendo las huellas sonoras de los héroes marginales}

Nosotros no vendemos un producto, vendemos un estilo de vida.

RENZO ROSSO

Lejos de las geografías prestigiosas de la ciudad, tenemos una cita marcada en el Hades. Ahí se oyen las voces de los testigos de las sombras que relatan la experiencia del gueto en que se convirtieron los barrios pobres de la periferia pobre y cerros de Rio de Janeiro, verdaderos vaciaderos de "residuos humanos" (Bauman, 2005). En los registros sonoros de los jóvenes MCs

\footnotetext{
12 SOARES, Luiz Eduardo. Pancadão no estômago. Originalmente publicado en el periódico O Dia, en 30 jun. 2002. Disponible en: www.luizeduardosoares.com.br/docs/uma viagem ao inferno.doc Acceso en: 30 nov. 2008.
}

Poligramas 37, primer semestre 2013, ISSN 0120-4130. 
(masters of cerimonies) que cantan en los "bailes" de comunidades encontramos, más que a ellos mismos y sus vivencias, el propio público de los espectáculos constituido por jóvenes que se reconocen en letras en las cuales aparecen sus historias, su visión de mundo, sus valores. El "baile" de comunidad es, por lo tanto, un ritual de reconocimiento donde representación y representados se encuentran y dialogan intensamente, compartiendo una memoria común.

La música funk afirma una dicción entrañablemente relacionada a un nuevo territorio expresivo: la periferia, y en este territorio engendra un discurso que excede lo individual; traduce la mirada del grupo, comunica las reglas no escritas de esa sociedad y las representaciones a través de las cuales los que ahí viven se miran. La repercusión de las letras de Funk Prohibido en la realidad de los residentes, interfiriendo profundamente en sus auto imágenes, nos permite pensarlo como un instrumento útil para redefinir o re-significar la propia idea de nación, proyectando en ese horizonte una concepción de espacio y medio social que tiene que ver con la visión de la favela como un país extranjero. Esta es una imagen recurrente en nuestro imaginario social y también presente en la manera como los residentes de estas comunidades perciben la relación que establecen entre ellos mismos y con la sociedad externa, plasmando en estos textos una visión de mundo que agrega y produce cohesión grupal al mismo tiempo que reafirma la exclusión del cuerpo más amplio de la sociedad. Al reflexionar sobre las representaciones de los propios jóvenes residentes de favelas que expresan ese conflicto a través del funk y, más particularmente, del Funk Prohibido, podemos concluir que muchos de estos sujetos periféricos se sienten extranjeros dentro de la nación o de la ciudad e intentan incorporarse a una otra "comunidad", identificada en la favela o, en el caso de los jóvenes en conflicto con la ley, en una red de favelas dominadas por una misma facción criminal. Carlos Lessa, en O Rio de todos os brasis nos llama a reflexionar sobre esta cuestión, pensando el tema desde la perspectiva de la estructuración de una otra comunidad nacional en los enclaves de la pobreza:

Cada favela carioca creó un territorio con estatuto propio y distinto de la ciudad. Creó sus propios códigos y dio origen a una micronación. Obligada a estructurarse para sobrevivir, es la obra 
máxima de una pobreza precariamente asistida y es la forma por la cual constituye un sucedáneo para las lagunas de la ciudadanía. ${ }^{13}$

Acaso convenga volver una vez más al tema. Otros autores también defienden la importancia de estea abordaje del tema al analizar la producción de discursos culturales en las "zonas de contacto" (PRATT, 1999). Jesús Martín-Barbero enfatiza en De los medios a las mediaciones que, "más que objetos de políticas, la comunicación y la cultura constituyen hoy un campo primordial de batalla política: el estratégico escenario que exige que la política recobre su dimensión primordial - su capacidad de representar el vínculo entre los ciudadanos, el sentimiento de pertenencia a una comunidad - para enfrentar la erosión del orden colectivo" (MARTíN-BARBERO, 2003, p. 15). El Funk Prohibido como un elemento bastardo del mundo de la cultura es también uno de estos campos en que se están librando pequeñas batallas identitarias por sujetos que buscan reafirmar o construir su pertenencia a una comunidad. Constituye, por lo tanto, a partir de las propias narrativas con que estos sujetos representan su mundo, un tipo de sentimiento de nación muy particular que se asocia ahora no al Estado nacional, sino a un territorio particular en donde el ente estatal no se inmiscuye y de lo cual se excluyó casi completamente. El Funk Prohibido, al narrar el microcosmos de la favela, se convierte, entonces, en un instrumento que ayuda a hombres y a mujeres a imaginar un grupo al cual podrían pertenecer. (Y aquí es inevitable la referencia a Benedict Anderson.)

En la misma línea de pensamiento de Ernest Renan en “Qu'est-ce qu'une nation?"14, Anderson propone que el fundamento de una nación es que los individuos que integran su cuerpo se acuerden de mucha cosa en común, y, además, se hayan olvidado mucha cosa también de modo colectivo. Se conforma, así, la idea de nación como "comunidad imaginada" (ANDERSON, 2008), la cual convocamos aquí para pensar una de las pequeñas naciones que se proyectan y ganan fuerza con el debilitamiento de la figura del Estado-nación como elemento estructurador de las identidades. Segundo Anderson, la nación "es imaginada como siendo intrínsecamente limitada"

\footnotetext{
13 LESSA, C. (2000) p. 297.

${ }^{14}$ Cf. RENAN, Ernest. Qu'est-ce qu'une nation?. In: __. Oeuvres complètes. Paris: Calmann-Lévy. 1947-61, vol. I, p. 887906.
}

Poligramas 37, primer semestre 2013, ISSN 0120-4130. 
(ANDERSON, 2008, p. 32.), ello porque posee fronteras bien definidas más allá de las cuales están los miembros de otras comunidades, a las que no se pertenece.

De esta forma, en un universo muy particular de disputas por mercados para el comercio de drogas ilícitas, el proibidão publicita una marca (CV, TC o ADA) que es (o pretende serlo) al mismo tiempo una identidad colectiva vinculada a las comunidades populares. Frente a eso, se alimentó constantemente la visión de rivalidad, según la cual para una facción, como, por ejemplo, el grupo integrado por las bandas criminales identificadas bajo el nombre de Comando Vermelho (el "nós" o "é nós"), todos los demás son enemigos ("a gente" o "alemanes", en el vocabulario nativo). La razón de ser de esas formulaciones discursivas que movilizan constantemente las narrativas de conflictos armados consiste ante todo en diferenciarse de lo que a ellos es externo. La pertenencia se construye, como sugiere Bauman (2003, p. 27-28), por la imposición y defensa de una frontera concreta o imaginaria que se impone entre "nosotros" ("nós") y "ellos".

En ese horizonte, vale recurrir a la comparación con el contexto de formación de las "comunidades imaginadas" para destacar el modo como los valores se establecen en el mundo de la pequeña nación por una dinámica propia que resignifica hechos silenciados o noticiados sólo en las páginas policiales de la prensa local. El imaginario particular derivado de esta forma característica de registrar y recordar el pasado en ciertos territorios populares cariocas definidos oficialmente como "aglomerados subnormales" ${ }^{15}$ tiende a crear mitos, promover héroes y cristalizar una memoria particular, desarrollándose una relación de constante diálogo y negociación con los valores generales que imperan en el ámbito mayor de la ciudad. A veces se contraponen a estos, pero sin negarlos del todo. En esta relación de tensión en la que diariamente los sujetos circulan por distintos territorios de la ciudad, se hace necesario reafirmar los valores a través del contraste no con la unidad social mayor en que la pequeña comunidad-nación está insertada, sino con otras unidades sociales de igual proporción y actuando en el mismo campo de valores y significados, como lo son las otras facciones o conjunto de favelas bajo un mismo dominio.

\footnotetext{
15 Según el lenguaje adoptado por el Instituto Brasileño de Geografía y Estadística (IBGE), son descritos como "aglomerados subnormales" los asentamientos irregulares conocidos por favelas, comunidades, invasiones, mocambos, palafitas, entre otros.

Poligramas 37, primer semestre 2013, ISSN 0120-4130. 
Las letras de los Funks de Contexto se presentan como una de las distintas formas de estructurar las ideas, valores y conductas de los individuos a partir de las influencias del grupo a que pertenecen. Aunque muchas veces haya sido nada más que figuraciones identitarias en regiones de frontera, la agenda del Proibidão de Facción, como lo dice su propio nombre, es casi siempre el combate al enemigo que, con su amenaza constantemente renovada, agrega un nuevo vigor al sentido de pertenencia al grupo. El predominio de la negociación en las relaciones con las fuerzas desproporcionales de las instituciones de la ciudad formal, aun con la policía delante de la cual el arma más adecuada parece ser el "arrego" (propina pagada a los policías para evitar la represión a la venta de drogas, en el lenguaje nativo), no se observa en el caso de la interacción con otras facciones. En este caso, se impone siempre la lógica del enfrentamiento y la confrontación. Pese a esto, cabe señalar que esta relación marcada por una beligerancia feroz se muestra mucho más acentuada en el plano de las formulaciones discursivas que en el plano de las prácticas cotidianas de las facciones de tráfico al menudeo. Y no sorprende que sea así, ya que es justo en el plan de las representaciones puestas en circulación por el Proibidão que se reafirman los códigos y los valores con destaque especial para los límites de la percepción que cada uno tiene de sí mismo. Esta percepción se reactualiza de modo enfático en una narrativa que, dado su carácter de ejemplaridad, subraya de modo insistente las infracciones y los castigos o sanciones previstos en el código, manteniendo en el aire de modo omnipresente la amenaza de exclusión de la comunidad.

A través de la lectura de esas letras que casi nunca asumen una forma fija, podemos sentir la comunidad como un escenario de antagonismos en los cuales la construcción de la identidad a través de la pertenencia a un universo específico se basa en estrategias contrastivas o de oposición: "nosotros" vs "ellos". En una rivalidad aparentemente irreductible, el mundo se parte entre "é nós" y "é a gente", como se puede deducir de la letra de funk "Chumbo quente na Nova Holanda" que dice: "sai da frente porque nós não é a gente" ${ }^{16}$, sintagma que según la semántica

\footnotetext{
${ }^{16}$ Parodia de otro proibidão intitulado "Bope chumbo quente", hecho en homenaje a los integrantes del Batallón de Operaciones Especiales de la policía de Rio de Janeiro. El texto original demuestra el hecho de que parte de las fuerzas de seguridad comparte el mismo ethos guerrero de los grupos criminales armados. La música presenta aún la intención explícita de legitimar la eliminación sumaria de bandidos que pasan a ser vistos como "enemigos externos" siempre que reaccionen a la acción policial Esta concepción del problema de la violencia relacionado al narcotráfico como un conflicto bélico entre naciones rige la política de seguridad del Estado hace por lo menos una década. Una variante de esta composición está disponible en portal electrónico: <http://www.youtube.com/watch?v=GfbTHGk5VTI\&feature=related>. Acceso en 15 dic. 2011.
} 
tradicional de la lengua portuguesa no tendría cualquier sentido. O no tendría el sentido que se desprende del dominio de un contexto en que se contraponen amigos ("é nós", expresión de pertenencia al Comando Vermelho) y enemigos ("é a gente", expresión que identifica la pertenencia al grupo de los “alemães", es decir, la facción criminal enemiga) ${ }^{17}$.

En un escenario cuyas fronteras de la nación comunitaria son frecuentemente movibles, elásticas y discontinuas, para que se pueda integrar cohesivamente fragmentos de territorio que están dispersos por toda la ciudad y pueden ser conquistados o perdidos a través de acción guerrera, el "proibidão" actuó como importante instrumento para desarrollar (indistintamente) pertenencia a la comunidad y al comando armado que domina la región. Proporcionó, como otros tipos de discurso de la memoria, una conexión entre personas que nunca se han visto, pero comparten una misma memoria y percepción de mundo. Hay una comunión entre ellos que se construye por medio de la palabra cantada. Ese discurso que tiene que ver con el modo como se comprende y como se representa el mundo se actualiza como aquello que los diferencia de los que no pertenecen a la comunidad, constituyéndose como el dominio de una "tradición inventada" común que permite la distinción entre el "nosotros" y "ellos" (HOBSBAWM, RANGER, 2006). De ahí surge un territorio poblado por héroes marginales que sólo cobran sentido o solamente son conocidos/reconocidos en el ámbito interno de la propia comunidad imaginada.

\section{El ethos guerrero: "Sólo no se puede huir"}

Si no mato, me muero. $Y$ si huyo, la moral no queda en pie.

Becerra da Silva en "Legítima defensa"

\footnotetext{
${ }^{17}$ En Brasil, el pronombre de segunda persona del plural (nós) tiene la variante informal a gente, largamente utilizada en los registros orales. Dada la gran importancia de esta oposición en las letras de funk, se prefirió mantener las formas originales "nós" (acompañado del verbo ser que no establece relación de concordancia con la primera persona de plural -nós somos-, sino que con la tercera persona de singular: é nós) y "a gente".

Poligramas 37, primer semestre 2013, ISSN 0120-4130. 
El aumento de la violencia en la ciudad a partir de la segunda mitad de los años de 1990 tiene un eslabón con el fortalecimiento del ethos guerrero, lo que ocurre no sólo entre las bandas armadas del tráfico al menudeo, sino también en otros segmentos de la sociedad que se relacionan más directamente con las prácticas o discursos ligados a estos grupos como, por ejemplo, las fuerzas policiales.

Se puede percibir la predominancia creciente de una actitud guerrera a partir del aumento de la fe en un santo popular como São Jorge: policía o traficante, no importa el rol en el enfrentamiento puesto en escena por las prácticas y metáforas de la guerra, es común la devoción al santo guerrero. Otro contexto adecuado para pensarse el fenómeno es el que nos ofrecen las letras de Funks Prohibidos en las que se construye y se refuerza el mito del traficante guerrero.

Vale resaltar que el patrón de comportamiento derivado del "mito de la masculinidad" (NOLASCO, 1995) con sus obligaciones y prerrogativas, es algo compartido por un universo más amplio de la comunidad que el restricto círculo de jóvenes que trabajan directamente para la facción criminal. Esos códigos desvelan la forma como el grupo social lee a sí mismo y como se representa. Es esta red de lecturas cotidianas del mundo periférico hechas por el propio subalterno que vamos a encontrar en las letras de Funk Prohibido como eco de un discurso que también aparece bajo otras formulaciones. Véase, por ejemplo, el caso de una residente de Rocinha -una de las favelas de donde provienen los testimonios del libro Morro, mulher- que narra una situación de violencia mientras externa los valores que dan sentido a su existencia en la cual se destacan vivencias que construyen un mundo donde las nociones de honor y vergüenza son fundamentales: "Hubo una blitz aquí en el cerro y los hombres (la policía) pusieron a los tipos (narcos) vestidos de mujer pa' bajarles la moral. Si fuera a mi hijo, yo preferiría su muerte." (O'GORMAN, 1984, p. 109).[“Teve uma blitz aqui no morro e os homem botaram todos os caras vestido de mulher pra baixar a moral deles. Se for meu filho fazer isto, eu prefiro a morte dele."]

Podemos percibir ahí que el juicio que el grupo social hace de los individuos está basado en valores o reglas comunes, que todavía consideran el honor masculino una virtud más valiosa que la propia vida. Jorge Luis Borges, hablando del mundo de las periferias semi-rurales del Buenos Aires de comienzos del siglo XX y de los valores que se puenían en circulación en las letras de tango, nos recuerda la índole sexual y la índole belicosa del género musical porteño, sugiriendo un Poligramas 37, primer semestre 2013, ISSN 0120-4130. 
vínculo entre ambas que podría ser encontrado en la raíz etimológica común de las palabras "varón" (hombre) y "virtud" (que en latín quiere decir fuerza viril o coraje). Virtus, sería un término derivado de vir, que significaba "hombre", pero también "guerrero" o "soldado". Se asociaría de ese modo, por lo tanto, la capacidad sexual y la capacidad guerrera como elementos constitutivos indisociables de la imagen pública del sujeto masculino. ${ }^{18}$

Se refuerza, con esto, el mito modelar del guerrero viril, valoroso, hombre impar por el coraje, pese a no ser invencible ni tampoco presentarse como una figura sin defectos, aspecto que lo mantiene en el plano humano.

Estos rasgos son característicos de un tono épico o caballeresco que en el funk encontramos ya totalmente degradado. En tiempos que imprimen la marca de la fugacidad a todas las existencias, con sujetos destinados a la rutina y al anonimato, ya no hay espacio para el heroísmo épico, salvo el de esta épica degradada, la heroicidad decaída de los infames que encontramos en las letras que narran las luchas entre facciones armadas, y más precisamente en las que tratan de la reconquista del Morro do Adeus. Una de las muchas versiones de "Tomamos o Adeus"19, especie de pequeña pesadilla épica cantada por MC Frank, hace el héroe reaparecer de las páginas policiales de la prensa diaria bajo la forma de bandidos de la periferia pobre de la ciudad al mismo tiempo que rescata del olvido los que no deben pasar sin dejar por lo menos el nombre registrado para su comunidad:

$$
\begin{aligned}
& \text { Ai que saudade do PT } \\
& \text { Neguinho fortalecia } \\
& \text { O moleque era braço } \\
& \text { P..., ele era cria }
\end{aligned}
$$

Vou mandar um papo reto

\footnotetext{
${ }^{18}$ BORGES, J. L. (1998) p. 134.

${ }^{19}$ Todos los Funks Prohibidos citados en este trabajo fueron sacados de CDs comprados en ferias populares de comunidades o en puestos de vendedores informales en donde este material se distribuye dentro de las favelas cariocas. En los casos en que se observó la posibilidad de acceso vía Internet, se informó en nota el portal en que la música y/o su letra está disponible.
}

Poligramas 37, primer semestre 2013, ISSN 0120-4130. 
Sabe o que é que aconteceu?

Ih $f .$.

Tomamo' o Adeus todinho

(..)

Sé é pra mandar na hora, escute o que eu vou dizer:

Bonde da Fazendinha, relíquia do MT

O bonde é preparado, meu mano, nós que é cria

Sai um bonde da Grota, outro da Nova Brasília

O bonde da Chatuba, sabe como é,

O bonde pesado, mano, partiu a pé

O bonde preparado é o bonde do Gordão

Bonde do BH, neguinho, Parque União

(..)

Tiro pra c..., o meu mano $\mathrm{BH}$

Doda revoltado, preste atenção,

É tiro pra c..., estilo Afeganistão

Então, ih f...

Tomamo' o Adeus todinho ${ }^{20}$

\begin{abstract}
${ }^{20}$ Música disponible en el portal YouTube, dirección electrónica: 〈http://www.youtube.com/watch?v=-gXo9P3HbGo>. La versión light de "Tomamos o Adeus" es demasiado conocida fuera de las favelas y se intitula "Cabelo encolheu". Presenta una letra que narra un otro aspecto de lo cotidiano de las periferias: "Ah, vou mandar un papo reto, essa vai para os guerreiros,/ Que têm una mulher que vai no cabeleireiro, gastou trinta reais e sabe o que é que aconteceu?/ Ih choveu! cabelo encolheu! (todinho)/ Ih, choveu, cabelo encolheu!/ Vou mandar un papo reto, neguinho, vê se me escuta!/ Se você fez escova, vê se leva o guarda chuva!/ Ô, não tô de caô, gata, não tô de gracinha/ Se você fez implante, alisante o chapinha:/ Tome muito cuidado, sabe o que é que aconteceu?/ Ih choveu, cabelo encolheu!" Disponible en: <http://www.letras.com.br/mc-frank/cabelo-encolheu>. Acceso en 30 nov. 2011. En este punto del texto, mantuvimos las letras de las músicas en original debido a la gran cantidad de expresiones y jergas.
\end{abstract}

Poligramas 37, primer semestre 2013, ISSN 0120-4130. 
Así las criaturas que pueblan las letras de "lo prohibido" cumplen un rol bastante central para las barriadas populares de Rio de Janeiro al presentarse como experiencia de aprehensión de una realidad invisible, innombrada, silenciada. La música habla de hechos sucios en una prosa de grandilocuencia a ras del suelo, que vuelve peatonal lo que antes era auratizado ("Saudades do PT, ai que saudade do Moral e o Zé Gordo era o nosso general... Meu mano Mi que não tá de brincadeira, vem o Pitoco com seu AK de madeira", MC G3). Esta crónica de los silencios de la grande urbe humaniza a los que están asignados a morir anónimamente en el infierno. Con la prosa simple e impactante encontrada por los subalternos para narrar el horror, prestigia y mitifica los héroes de la pequeña comunidad imaginada. Se trata de una representación de la imperfección social a través de un lenguaje también imperfecto, marcado por la oralidad de los bordes de la ciudad y la sociedad, llena de jergas y palabrotas. Con una narrativa grosera y brutal, los MCs hacen un relato que dibuja esa realidad, cuentan las historias de vida de los protagonistas del narco, de sus victimas y de los habitantes de las barriadas populares. Como una de esas miradas reveladoras que traen a público, sin tapujos, escenas de la batalla librada entre narcos, policías, milicias paramilitares y brigadas de elite de las fuerzas del orden en zonas de la ciudad que los propios órganos de la prensa presentan a través de metáforas de guerra, "Tomamos o Adeus" busca grabar en la memoria de una facción en prolongado conflicto armado con otra banda criminal la "histórica" conquista llevada a cabo por el Comando Vermelho del territorio que, por lo menos en un plano mítico, se presenta como el hecho más importante para la identidad del grupo. Se presenta en destacado el guerrero muerto en el presente de la enunciación pero que asumió una posición de comando en la "gesta" bárbara. Se nos informa la estrategia de desplazamiento para avanzar sobre el área del oponente ("o bonde ... partiu a pé"), y el nombre de las comunidades que integraran el proceso de cooptación de alianzas con los grupos armados de otras favelas para la formación de la partida ("bonde" ${ }^{21}$ ) que va a invadir el territorio enemigo (de los "alemanes"). Además de esto, la voz enunciadora pone una atención especial al acto de listar a los principales "guerreros" que, en "estilo Afeganistão", participaron en la retomada de Adeus, enfatizándose las cualidades de todos o de algunos en particular a causa de las virtudes guerreras ("o bonde é preparado", "Doda revoltado") o por los critérios de pertenencia

\footnotetext{
${ }^{21}$ Conforme las necesidades de la estructura de la banda narco, hombres jóvenes que viven en una misma favela o en favelas amigas, son reclutados a formar una partida (la denominada bonde) para transportar droga o armas de una favela para otras o para invadir un territorio del vecindario controlado por un comando rival.
}

Poligramas 37, primer semestre 2013, ISSN 0120-4130. 
caracterizados por el vínculo con una determinada área periférica por ser ésta su lugar de nacimiento ("nós que é cria").

En otra versión de esta misma música, se resalta la reunión previa para proyectar las estrategias de invasión al campo enemigo y la importancia del poderío bélico, con mención directa a los "caños" o "púas" ("bicos"), en un discurso entrecortado por el insistente estribillo en conmemoración a la conquista que, en algunas versiones, aparece coronada por el hecho de plantar la bandera con los colores de la facción (rojo) en lo alto del cerro ("morrão") dominado. Y, por fin, como no podría faltar en un discurso que, más que la crónica de la conquista de un territorio, actúa en el proceso de cohesión identitaria, “creándose una memoria épica que fortalece el lazo simbólico entre diferentes cuadrillas agrupadas bajo la denominación de Comando Vermelho" ${ }^{22}$, son mencionados los nombres de los dos capos más grandes: protagonista y antagonista de la acción guerrera que se destacaron en el imaginario de las barriadas populares y en la mitología del crimen a lo largo los últimos veinte años, Orlando Jogador y Uê:

\section{(...)}

Vou mandar un papo reto

Sabe o que é que aconteceu?

O bonde da Fazenda tomou o Adeus

Se liga no papo, eu não tô de caô

Relíquia das relíquias do Orlando Jogador

(...)

O meu bonde, sem neurose, sempre fortaleceu

Bico pra c... e partiu lá pro Adeus

Os mano sinistro fizeram a reunião

Subiram o Adeus, só mandaram rajadão

Se liga no papo, sabe o que é que aconteceu?

\footnotetext{
${ }^{22}$ ALVITO, M. (2001) p. 77.
} 
Ih, f..., tomamo' o Adeus todinho

(...)

Uê ficou $f . . .$, mano, foi pro pneu

É o bonde preparado, sabe o que é que aconteceu?

Nós tomamo' o Adeus

$\mathrm{Ih}, \mathrm{f} . . .^{23}$

Sin embargo, la narración recurrente de la conquista del Cerro del Adeus, que parece referirse a algo que estaría más allá del tiempo, en una especie de plano mítico que no llega a ser afectado por los cambios históricos como la alternancia de facciones en el dominio de un mismo territorio, parece constituirse en una excepción. Las letras de los proibidões de facción se presentan casi siempre como el registro de un hecho o deseo circunstancial, caracterizándose en el propio universo temático el elemento que lo define como construcción desechable. Podríamos dar como ejemplo de este factor que marca la condición poco duradera de los proibidões el proyecto de invasión y conquista de una comunidad rival que no llega a concretarse, sino que, al revés, es esta que se convierte en fuerza expansionista, conquistando el territorio desde donde partía la amenaza. Después de años de guerra particular en los que en incontables letras el grupo criminal que dominaba la comunidad de Vigario Geral amenazó a la vecina Parada de Lucas ("Lucas vai virar (V"), fue de hecho de esta favela (Parada de Lucas) de donde partió el "bonde" que fue a invadir y conquistar el vecindario enemigo. Otro ejemplo de esa condición pasajera de las letras del Funk Prohibido está en el acto de nombrar al capo enemigo con referencias que debilitan su virilidad, con lo que se busca desmoralizar de paso a toda la facción rival. El criminal cuyo que aparece hoy en una letra escrita con esta intención en la semana siguiente puede estar muerto o desaparecido y el discurso pierde completamente su sentido. Tal es el caso del funk que dice que el capo de La facción Amigos dos Amigos (ADA) llevaba bragas: “Nosso bonde é bolado, mete bala na Getam/ Vou dar só tapão na cara do comédia do Gangan/ Eu vi un tal de Linho rebolando de calcinha").

\footnotetext{
${ }^{23}$ Música disponible en el portal YouTube, dirección electrónica: <http://www.universoalegria.com.br/videos/single/id/gXo9P3HbGo>. Acceso en 18 dic. 2011.
}

Poligramas 37, primer semestre 2013, ISSN 0120-4130. 
Salvo las que registran, exponen y archivan lo que los dignos de memoria han hecho aquí en este mundo, la mayoría de las músicas grabadas en los shows de los MCs en bailes de comunidades tienen una vida demasiado corta, y hasta puede que un determinado registro sonoro de gran éxito en el circuito alternativo por un periodo llegue a desaparecer completamente sin dejar vestigios siquiera en YouTube. Basta, por ejemplo, que el baile haya sido organizado en homenaje a un cumpleañero cuya imagen con el paso del tiempo se convierta en la de un traidor del grupo. Con esto, las referencias elogiosas registradas en la grabación de las músicas cantadas en la fiesta se vuelven objeto de un olvido sistemáticamente construido.

Se trata de una producción para el ahora, crónica do lo inmediato, como el periodismo diario. De modo que cuando algunas letras empiezan a circular en CDs piratas o cuando son subidas a YouTube ya están desatualizadas puesto que hablan de realidades que ya han evolucionado o se han transformado radicalmente. Pero esa fluidez inaprensible de una red de discursos en que se condensa lo efímero se sedimenta en variantes construidas alrededor de una base común, lo que nos permite identificar patrones en la dinámica de estos espacios y en la acción de sus actores principales. Vale decir, para una precisión mayor del enfoque de este objeto tan conflictivo y múltiple, que lo que buscamos es precisamente el punto en que el registro trasciende la circunstancia y el recorte del discurso prohibido excede la mirada del autor y sus negociaciones con distintos factores involucrados en el rito de la bailanta.

Reconocemos, sin embargo, que el discurso del Funk Prohibido es esencialmente determinado por las circunstancias. Está relacionado a los eventos que marcan la situación espacial y temporal en que es difundido, asumiendo un vínculo indisociable con el espacio y el momento histórico en que se promueve el espectáculo. Como no podría dejar de ser, el propio público ejerce una gran influencia en el proceso de enunciación y el MC siempre lo lleva en cuenta al subir al escenario. Dependiente de todos estos factores y diferentemente de otros subgéneros de funk, el discurso del Proibidão de Contexto produce registros sonoros profundamente limitados en su difusión, teniendo en la casi totalidad de los casos una vida muy efímera en lo que atañe a las selecciones que integran las colectáneas copiadas y distribuidas en los mercados informales o en las ferias de las comunidades populares.

Poligramas 37, primer semestre 2013, ISSN 0120-4130. 
Un funk como "Rap da felicidade" o "Cabelo encolheu" permanece tan actual hoy como en el momento en que fue producido o empezó a difundirse, apareciendo como discursos no marcados por cualquier circunstancia particular. Los Proibidões de Facción, a su vez, dependen casi integralmente de las circunstancias y demuestran en eso el carácter central de su condición desechable. En este ámbito se encuadran de modo especial los Funks Prohibidos que dramatizan la rivalidad entre facciones, representando un enfrentamiento o un triunfo particular en la "guerra sin fin" en la que se enfrentan traficantes pertenecientes a "comandos" rivales. Estos registros sonoros de una determinada letra sólo consiguen permanecer actuales mientras dura aquella particular configuración de fuerzas que originó el rap de exaltación.

Por ejemplo, el verso "A Rocinha é CV e Comando não é comandado", cantado en bailes de comunidades dominadas por el Comando Vermelho, no más corresponde a la realidad cuando la facción Amigos dos Amigos conquista esta favela de la Zona Sur carioca, haciendo que los proibidões del Comando Vermelho dejen de celebrar el dominio sobre este territorio y transfieran el foco del discurso hacia proyectos o deseos de invasión del área ahora en posesión de su oponente: “Já tomamos o Vidiga/ Só tá faltando a Rocinha/ Fale quem quiser falar/ Rocinha vai vermelhar" (MC Max) o "O bonde partiu pra Rocinha dentro do caminhão da Light" (MC Didô).

Otra tipología de letras con gran potencial de obsolescencia involucra aquellas que mencionan por su nombre a los bandidos vivos que ocupan una posición destacada en la jerarquía del tráfico. En estos casos, la validez de la letra sólo se mantiene mientras dura el periodo de poder del jefe de la cuadrilla referido en la letra. Un buen ejemplo es el proibidão que exalta el liderazgo de la banda criminal en la letra que dice: "Oi quem vem puxando o bonde é o Tota e o Faustão" en oposición a "Bala no Jansen e bala no Tota" cantada tiempos después ${ }^{24}$.

Sin embargo, en el caso de los discursos elegíacos, las manifestaciones de añoranza, a causa del propio objeto de la enunciación ser el desaparecimiento de un personaje a cuya imagen se pretende dar un carácter de permanencia, la obsolescencia de las letras no se observa de la misma forma. Personajes importantes en el mundo del crimen carioca como Orlando Jogador siguen

\footnotetext{
${ }^{24}$ Antônio José Ferreira, el Tota, que comandó el tráfico de drogas en el conjunto de favelas de Alemão y llegó a ser considerado por la prensa el traficante más buscado de Rio, recibió homenaje en varios proibidões hasta que, al ser muerto, en septiembre de 2008, por integrantes de su propia facción, aparece en las crónicas prohibidas asumiendo otro rol: el de traidor ajusticiado por los suyos.
} 
presentes en letras de Funk Prohibido muchos años después de su muerte. Pero no sólo los bandidos cuyas figuras tuvieron fuerte repercusión en la imprenta o que murieron mientras ocupaban una alta posición en la jerarquía interna del mundo narco merecen pasar a integrar, vía discurso de lo prohibido, la memoria social de estos micro espacios de la urbe. Figuras del segundo o tercero escalón de la estructura criminal de una simple favela, como Nino y Michinho, también pueden incorporarse a la memoria de determinados territorios de la ciudad, como Parque União o Nova Holanda, en el Complexo de Maré, tal como se puede ver en esta letra de un proibidão de 2006:

\author{
Añoranza eterna de Nino y de Michinho \\ Que se fue, pero seguro el recuerdo no tendrá fin \\ Puedes estar seguro de que perdemos dos hermanos \\ Que sobre todo eran pura disposición \\ Recuerdo de los hermanos del Comando Vermelho \\ Sólo andaba pesado, echaba bala en los Terceiro \\ En Parque União, sólo bandido cabuloso \\ 157 bolado, PU, “bonde” de Zé Gordo ${ }^{25}$
}

A través de discursos como éste, muchos individuos que integran esta cultura tan particular encuentran una forma de escapar de la no-existencia que es morir sin dejar memoria de sus actos, de su pasaje por la vida, salvo en los registros de ocurrencia de delitos que van a perderse en los archivos policiales o en la crónica roja de la prensa local. Tal vez la principal característica de los Otros, desde los bárbaros y esclavos de la antigüedad hasta las masas de las periferias urbanas del siglo XXI, sea la imposibilidad de acceso a los instrumentos de voz y, a falta de éstos, la ausencia de registros de su experiencia para las generaciones siguientes. Los que no tienen acceso a la palabra escrita o a los medios de representación están condenados, por lo tanto, a una zona obscura que no resiste al asedio de cronus. Alba Zaluar, en un ensayo intitulado "Rio de Janeiro: fronteiras

\footnotetext{
${ }^{25}$ MC Duda do PU. "Saudades eternas do Nino y do Michinho". CD de Funk Prohibido no identificado. Comprado en Parque União (Favela de Maré) en 2006.

Poligramas 37, primer semestre 2013, ISSN 0120-4130. 
urbanas" cuestiona: "Tendrían los hombres (y mujeres) abandonado integralmente la búsqueda, aun vana, de la fama, de la gloria, o de aquello que los griegos llamaban «inmortalidad», en las ciudades modernas?"26 Podemos contestar enfáticamente que no. Esta búsqueda continúa a ser observada en diferentes ámbitos como el mundo de los deportes o de las artes y, más particularmente, en el universo de las fronteras urbanas de que hablamos aquí, en la actividad guerrera vivida por los que libran la lucha por territorios o actúan en la defensa de los intereses de una facción criminal.

Protagonizar una letra de funk no significa la inmortalidad, pero sí un triunfo pasajero sobre el olvido. En la letra de "Vivos somos traicionados", MC Didô canta las perspectivas que se dibujan en el horizonte de los que actúan en la órbita del grupo armado:

\author{
Vivos somos traicionados \\ Reclusos, olvidados \\ Muertos, sólo dejamos añoranza \\ Es Paz, Justicia y Libertad ${ }^{27}$
}

Joaquín María Aguirre, en el ensayo "Héroe y sociedad", destaca el vínculo entre los valores sociales y los valores heroicos, derivando estos de los valores compartidos en una sociedad con cohesión suficiente como para proyectar a todos (o para la mayoría de sus miembros) un ideal de virtud, independiente de lo que el grupo conciba por virtud:

para que aparezca el héroe, la sociedad ha de tener un grado de cohesión suficiente como para que existan unos valores reconocidos y comunes. Sin valores no hay héroe; sin valores compartidos, precisando más, no puede existir un personaje que permita la ejemplificación

\footnotetext{
${ }^{26}$ ZALUAR, Alba. Rio de Janeiro: fronteiras urbanas. In: Item.6: Fronteiras. Rio de Janeiro: Casa da Palavra, março 2003, p. 21. [p. 18-33.]

${ }_{27}$ MC Didô. "Vivos somos traídos". Disponible en: <http://www.youtube.com/watch?v=67VluAqat9k>. Acceso en 30 nov. 2011.
}

Poligramas 37, primer semestre 2013, ISSN 0120-4130. 
heroica. El héroe es siempre una propuesta, una encarnación de ideales. La condición de héroe, por tanto, proviene tanto de sus acciones como del valor que los demás le otorgan. ${ }^{28}$

Muchos cambios se registraron, a lo largo de los últimos diez años, en el imaginario asociado a las favelas, y la figura del héroe no podría quedarse ajena a ellos si llevamos en cuenta que su condición o la propia concepción de la heroicidad depende de los valores dominantes y van a variar, por tanto, según el contexto histórico. En este sentido, se destaca la importancia del funk como un instrumento de vehiculación de mensajes que crean a los héroes a partir de un modelo de virtudes compartido por las pequeñas naciones que son las comunidades populares bajo el dominio de facciones armadas del narcotráfico.

En contrapunto no sólo con los códigos y leyes, sino también con la concepción de virtud dominante en la ciudad formal, estas comunidades, o una parte significativa de ellas, presentan una adhesión social a los valores representados por el héroe marginal. Cada grupo fabrica sus héroes según su propia imagen, pero al mismo tiempo es también constituido por los discursos que se difunden en lo colectivo, y, por eso, podemos hacer un esfuerzo para leer a estos grupos vinculados a la violencia armada, pero también, por extensión, a las comunidades dominadas por ellos, a partir de sus héroes y de los discursos que narran estas vidas que se pretenden impares. Zygmunt Bauman llama la atención para esta relación cruzada entre representaciones y realidad representada:

Las vidas vividas y las vidas contadas son, por esta razón, estrechamente interconectadas y interdependientes. Podremos decir, lo que es paradójico, que las historias de vidas contadas interfieren en las vidas vividas antes que las vidas hayan sido vividas para que sean contadas... ${ }^{29}$

\footnotetext{
${ }^{28}$ AGUIRRE, Joaquín María. Héroe y Sociedad: El tema del individuo superior en la literatura decimonónica. Revista Espéculo, Revista de Estudios Literarios. Facultad de Ciencias de la Información Universidad Complutense de Madrid. Año I, n. 3, 1996. (Revista Digital Cuatrimestral). Disponible en: <http://www.ucm.es/info/especulo/numero3/heroe.htm>. Acceso en 30 nov. 2011. (Destacado nuestro.)

${ }^{29}$ BAUMAN, Z. (2008) p. 15.

Poligramas 37, primer semestre 2013, ISSN 0120-4130. 
Los valores son transmitidos, con o sin intención, a partir de formulaciones discursivas puestas en circulación en un grupo y éstas acaban por ejercer un rol fundamental en el proceso de socialización de los individuos. Insertándose en el universo más amplio de los cambios sociales simbólicos, el Funk Prohibido difunde una representación que interfiere de modo profundo en el desarrollo de creencias, valores y conductas de los sujetos representados. Según Stuart Hall "el modo como las cosas son representadas y las 'maquinarias' y regímenes de representación en una cultura ejercen un rol constitutivo, y no sólo reflexivo, después de lo que ocurrió" ${ }^{30}$

El Funk Prohibido tuvo su momento culminante al alrededor de la mitad de la primera década del siglo XXI cuando los grandes nombres del proibidão se volvieron también los grandes nombres del funk en general. A comienzos de la segunda década del siglo XXI, sin embargo, percibimos que el funk está en una encrucijada. El oyente más atento o el frecuentador más asiduo de las bailantas ("bailes") seguramente habrá observado la diferencia patente en las músicas que tocan desde los últimos meses de 2010 y concluirá inevitablemente que el funk está terminando un ciclo.

El funk sigue popular en las periferias y favelas, pero se volvió más abierto a negociaciones con un número más grande de actores sociales y aparece menos marcado por el relato directo y brutal de la vida en la comunidad. Se pierde parte de su carácter de expresión cruda de la realidad y, por tanto, de su violencia visceral, pero por ello transita mejor por los diferentes espacios de la ciudad.

Aquella realidad que dio origen al Proibidão de Contexto con la prohibición de los bailes de club y la proliferación de los bailes de comunidad ya no existe más. El funk, tal como los territorios de donde estuvo proscrito por una década, vuelve a integrar el mapa geográfico, social y cultural de la ciudad.

El funk, que se transformó en uno de los instrumentos más adecuados para comprender la cultura juvenil de la periferia carioca, asumió una nueva dicción cuando lo proscribieron hacia los espacios en donde se imbricó con el mundo del crimen, pasando a destacarse, junto con el narcocorrido

\footnotetext{
${ }^{30}$ HALL, Stuart. In: BAUMAN, Z. (2008) p. 15. 
mexicano y la cumbia villera argentina, como más un producto de las subculturas de la violencia. Ahora, en un movimiento inverso, parece estar abandonando los espacios de proscripción y se vuelve imposible negar que el estilo actual del movimiento evidencie una contramarcha. La reconfiguración del tráfico de drogas, con el surgimiento de una nueva generación de narcos sin fusil, provocó una urgente y necesaria reconversión del producto con que trabajaban los MCs de funk: las narrativas de representación identitaria. El mundo que los cercaba era denominado por códigos similares a los que ellos ponían en escena a través de sus letras. En un cuadro como ése, la crisis vivida por el proibidão y el surgimiento de nuevas formas de expresión en el mundo funk están implicados en el fenómeno de desaparecimiento de las condiciones necesarias para la producción del discurso del Funk de Facción. Y hablamos aquí tanto de las condiciones materiales (la progresiva disminución de los "bailes" de comunidad en áreas dominadas por el tráfico) como de las imaginarias (las radicales alteraciones en un contexto de sociabilidad basado en el ethos guerrero).

La pérdida de dominio sobre el territorio por parte de las facciones armadas produjo en los individuos que las integraban una percepción de la inviabilidad de aquél modelo de tráfico, lo que fue también la señal para los MCs del ocaso de Funk Prohibido. Cada época trae consigo una concepción propia del rol a ser desempeñado por los sujetos de una comunidad particular, reforzando o debilitando un repertorio de visiones de mundo en donde se incluyen la heroicidad guerrera o la idea de virtud, lo que irá también definir dinámicamente el rol de las representaciones para esa comunidad. Teniendo eso en cuenta, debemos concluir que el discurso actual del funk carioca no podría dejar de acompañar y referirse directa o indirectamente en sus letras un evento que trajo cambios profundos para el escenario de la producción de los discursos.

A partir de la ceremonia informal de izar la bandera nacional llevada a cabo por las tropas de "pacificación" en lo alto del Morro do Alemão, hecho que simbolizó la ostentación de un poder que no podría ser combatido, se demuestra que la estrategia de confrontación adoptada no sólo por los jóvenes que constituyen el brazo armado del mundo narco, sino por la misma policía a través de sus fuerzas especiales, ya no era válida, puesto que el "enemigo" optaba por huir sin luchar, abdicando del territorio dominado. La facción o el capo local no puede enfrentarse a un oponente que trasciende a su fuerza de combate, y esto pasa cuando el enfrentamiento armado

Poligramas 37, primer semestre 2013, ISSN 0120-4130. 
tiene del otro lado no a los hombres de la policía local con sus armamentos tradicionales, sino a las tropas del Ejército y de la Marina con tanques blindados, helicópteros y equipos de visión nocturna. La disparidad de fuerza actuó decisivamente como elemento de disuasión. Este fue también el momento de crisis de un modelo de representación de la realidad fundado en las metáforas de la guerra. Ello demuestra que el centro de la cuestión está en la disputa de representaciones sociales construidas en los momentos de gran miedo cuando se proyectan figuraciones del Otro como enemigo a ser combatido. Era necesario desmilitarizar la imaginación de todos los lados involucrados en el conflicto (facciones criminales, policía, prensa radial o televisiva y sociedad en general).

Para una generación que creció bajo la influencia de estas figuraciones de subjetividad que dictaban rígidas reglas de conducta y reforzaban un estilo de masculinidad, pero también, a la par, era marcada por las experiencias que transformaban el mundo a su alrededor, ese giro cultural fue una verdadera onda modernizadora: formas fijas empezaron a ganar fluidez y tanto el tráfico de menudeo como el funk empezaron a vivir su momento líquido. El lugar desde el cual hablaban los MCs (más que la comunidad geográfica, la facción que la territorializaba) ya no existe con la configuración antes presentada, la de una especie de para-Estado. Con este reconocimiento, se abren las puertas para incursiones en un discurso funk polimorfo en que se diversifican los temas, los estilos y las vertientes.

Reformateado a partir de negociaciones varias que se observan en este nuevo momento, el Funk Prohibido fue, a su vez, progresivamente "domesticado" con vistas a insertarse en los nuevos nichos de mercado a través de una dicción menos agresiva y violenta. En este nuevo escenario, el alter ya no podría más contar su(s) historia(s) con el lenguaje de la barbarie.

\section{Bibliografía}

Alvito, Marcos. As cores de Acari: uma favela carioca. Rio de Janeiro: Editora FGV, 2001.

Anderson, Benedict. Comunidades imaginadas: reflexões sobre a origem e a difusão do nacionalismo. Trad. Denise Bottman. São Paulo: Companhia das Letras, 2008. 
Bauman, Zygmunt. Comunidade: a busca por segurança no mundo atual. Trad. Carlos Alberto Medeiros. Rio de Janeiro: Jorge Zahar Editor, 2003.

A sociedade individualizada: vidas contadas e histórias vividas. Trad. José Maurício Gradel. Rio de Janeiro: Jorge Zahar Editor, 2008.

- Vidas desperdiçadas. Trad. Carlos Alberto Medeiros. Rio de Janeiro: Jorge Zahar Editor, 2005.

Borges, Jorge Luis. Evaristo Carriego. Madrid: Alianza, 1998.

Cecchetto, Fátima Regina. Violência e estilos de masculinidade. Rio de Janeiro: Editora FGV, 2004.

Damatta, Roberto. Conta de mentiroso: sete ensaios de antropologia brasileira. 2a ed. Rio de Janeiro: Rocco, 1994.

Herschmann, Micael. Abalando os anos 90: funk e hip hop: globalização, violência e estilo cultural. Rio de Janeiro: Rocco, 1997.

. O funk e o hip-hop invadem a cena. Rio de Janeiro: Editora UFRJ, 2000.

Hobsbawn, Eric J, Ranger, Terence. A invenção das tradições. Trad. Celina Cardim Cavalcanti. 4ạ ed. São Paulo: Paz e Terra, 2006.

Lessa, Carlos. O Rio de todos os Brasis. Rio de Janeiro: Record: 2000.

Maingueneau, Dominique. Cenas da enunciação. Org. Sírio Possenti e Maria Cecília Pérez de Souza-e-Silva. Trad. Maria Cecília Pérez de Souza-e-Silva et al. São Paulo: Parábola, 2008.

Martín, Barbero Jesús. Dos meios às mediações: comunicação, cultura e hegemonia. Trad. Ronald Polito e Sérgio Alcides. 2aㅡ ed. Rio de Janeiro: Editora UFRJ, 2003.

Nolasco, Sócrates. O mito da masculinidade. Rio de Janeiro: Rocco, 1995.

- De Tarzan a Homer Simpson: banalização e violência masculina em sociedades contemporâneas ocidentais. Rio de Janeiro: Rocco, 2001.

O’Gorman, Frances. Morro, mulher. São Paulo: Edições Paulinas, Fase, 1984.

Pratt, Mary Louise. Os olhos do império: relatos de viagem e transculturação. Trad. Jézio Hernani Bonfim Gutierre. Bauru, SP: EDUSC, 1999.

Imagen 1 


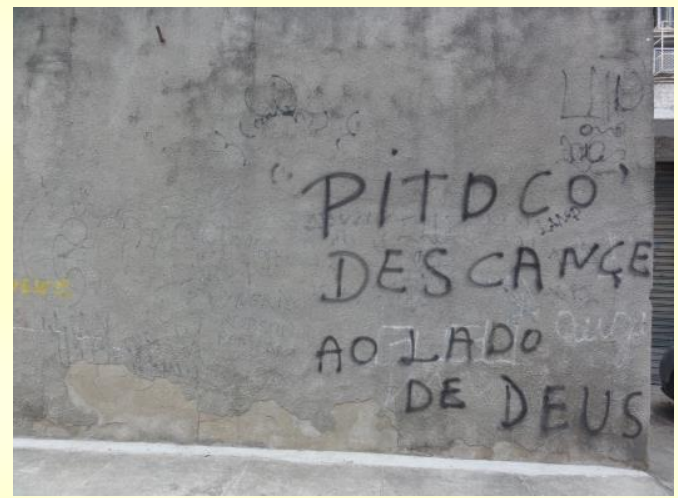

Imagen 2

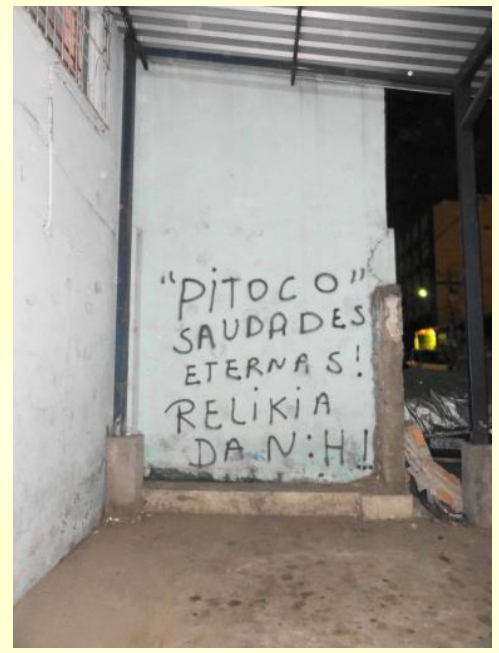

Imagen 3

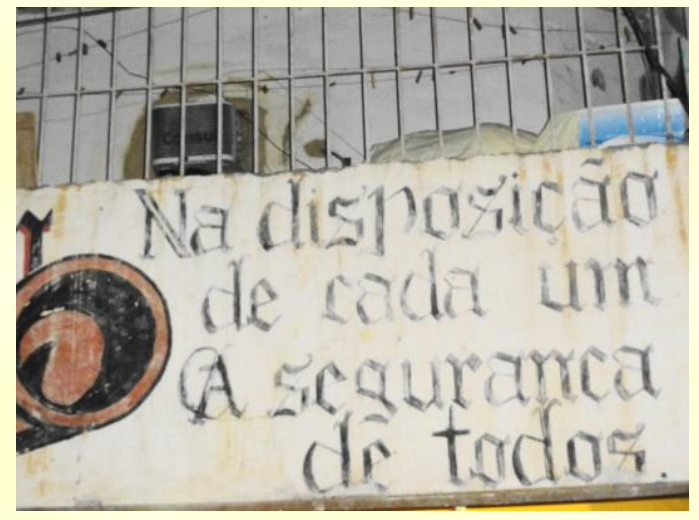

Imagen 4

Poligramas 37, primer semestre 2013, ISSN 0120-4130. 


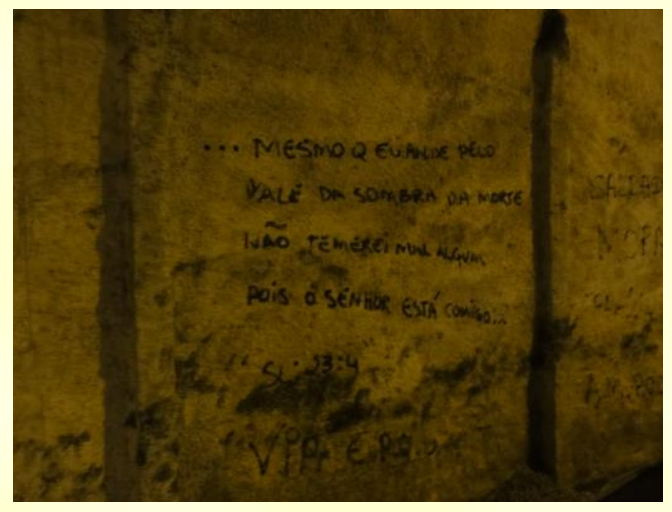

Imagen 5

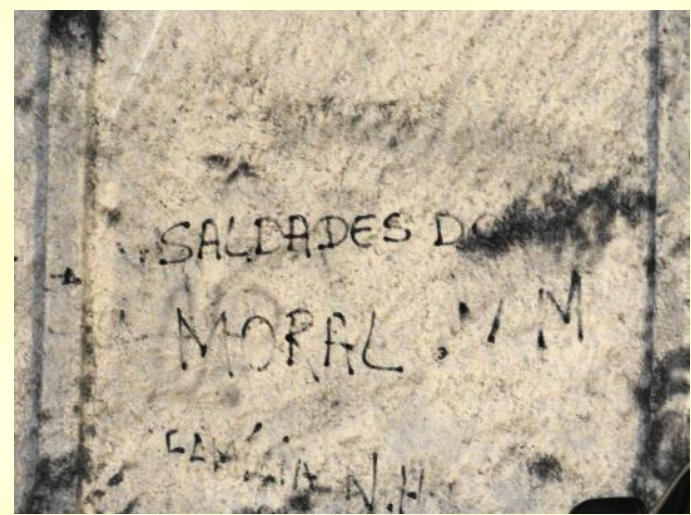

Poligramas 37, primer semestre 2013, ISSN 0120-4130. 